\title{
A comparative Study of Clinicopathological Characteristics and Expression of Basal Markers (CK5/6 \& EGFR) in Triple Negative and Non Triple Negative Breast Carcinomas in Kashmir Valley
}

\author{
Subuh Parvez Khan, Syed Besina Yasin and Fiza Parvez Khan \\ Department of Pathology, Sher e Kashmir Institute of Medical Sciences, Soura ,Srinagar, J\&K, India
}

\begin{abstract}
Background: The aim of this study was to compare the clinicopathological characteristics of Triple Negative Breast Carcinomas with Non Triple Negative Breast Carcinomas (NTNBC). Evaluation of expression of Epidermal Growth Factor Receptor (EGFR), CK5/6 in TNBC and their comparison with NTNBC was done.

Methods: 25 TNBC and 35 NTNBC were selected. The clinicopathological parameters of these two groups were compared. Each group was further immunostained for basal markers(CK5/6 and EGFR).The expression of markers in these two groups was studied and compared with each other.

Results: The mean age of TNBC and NTNBC were 47 and 49 years respectively. The majority (48\%) of cases from TNBC as well as NTNBC (45\%)were in size range of 2-5 cm(T2 stage). IDC-NOS was predominant histological type seen in $92 \%$ of TNBC and $100 \%$ NTNBC.TNBCs had a significantly higher tumor grade than NTNBC at presentation. LVI was seen in $40 \%$ TNBC cases and $42 \%$ NTNBC cases. Majority (52\%) of TNBC cases were node negative while majority (37.14\%) of NTNBC cases belonged to N1 stage. IIA was the most common stage in $36 \%$ TNBC cases . In NTNBC, majority of the cases (34\%) belonged to Stage IIIA.Expression of basal markers was significantly associated with triple negative breast cancers.

Conclusion: TNBCs had a significantly higher tumor grade than NTNBCs at presentation. Expression of basal markers was significantly associated with TNBCs. Since EGFR was significantly associated with triple negative phenotype, TNBC could potentially benefit from EGFR targeted therapeutic strategies.
\end{abstract}

Keywords: Cytokeratin, EGFR, Triple Negative Breast Neoplasms.

\section{Introduction}

Breast cancer is the second most common cancer in the world and, by far, the most frequent cancer among women'1. Breast cancer is a heterogeneous disease and it encompasses a variety of entities with distinct morphological appearances and clinical behaviours. In recent years it has been evident that this diversity is the result of genetic alterations. ${ }^{2}$

Currently, the most widely used classification system of breast cancer combines histo-morphological information (such as histological subtype and grading) as well as TNM staging information. ${ }^{3,4} \mathrm{~A}$ new approach to classify breast tumours using molecular characteristics was first described by Sorlie et al. ${ }^{5}$

Triple-negative breast carcinomas lack the expression of estrogen receptor, progesterone receptor and Her2. Although patients with TNBC tend to have a poor prognosis, only chemotherapy is expected to be effective because no therapeutic targets have yet been established. Histological types of TNBCs mainly comprise of highgrade invasive ductal carcinoma, no special type [solid- tubular carcinoma (or atypical medullary carcinoma), invasive ductal carcinoma with a large central acellular zone], typical medullary carcinoma, and metaplastic carcinomas.

They can be classified into two subtypes: basal and nonbasal phenotype ${ }^{6}$. Basal type was defined as CK5-/6-positive and/or EGFR-positive, and nonbasal type was defined as having no expression of these two markers. Although the triple-negative phenotype has been considered as sufficient to identify the 'basal-like' tumours, increasing evidence has shown that the terms 'basal-like' and 'triple-negative' are not synonymous. ${ }^{2}$ The triple-negative group of breast cancer is not a homogeneous disease entity. However, a substantial fraction of these tumours belongs to the basallike tumour type, which does form a homogeneous group.

The basal-like group comprises $8 \%$ to $20 \%$ of all breast cancers. ${ }^{7,5,8-15}$ The majority of these tumors are ductal of no special type, but occasionally are tubular mixed,,${ }^{14}$ metaplastic, ${ }^{16}$ or medullary cancers. ${ }^{17}$ They have common features including younger patient age, high 
histologic tumor grade, marked cellular pleomorphism, high nuclear-cytoplasmic ratio, lack of tubule formation, high mitotic index, frequent apoptotic cells, scant stromal content, a pushing border of invasion, central geographic or comedo-type necrosis. Basal-like cancer is associated with an aggressive clinical history, development of locoregional and distant metastasis (particularly in the first 5 years, ${ }^{12}$ shorter survival, and a relatively high mortality rate. ${ }^{13,14}$

\section{Materials and Methods}

The study was conducted in the Department of Pathology of Sher-e-Kashmir Institute of Medical Sciences (SKIMS), a tertiary care referral centre of Kashmir valley for a period of 7 years from December 2008 to November 2015.This study is approved by institutional review board.All the patients diagnosed with primary breast cancer enrolled in our hospital during this duration were analysed. 60 cases of invasive breast cancer were selected whose complete clinical profile and the paraffin block was available. Based on the hormonal status, the 60 cases were divided into 25 Triple Negative Breast Carcinomas(TNBC) and 35 Non Triple Negative Breast Carcinomas (NTNBC). The clinicopathological parameters of these two groups were compared.

Triple negative category included those cases which were negative for ER, PR and Her 2. Non triple negative category included those cases which were ER/PR positive, Her 2 negative or ER/PR positive, Her 2 positive or ER/PR negative, Her 2 positive. Each group was further immunostained for CK5/6 and EGFR(Biocare antibodies,India).The expression of markers in these two groups was studied and compared with each other.

Formalin fixed and paraffin embedded section were cut and placed on glass slides coated with $0.5 \%$ poly $\mathrm{L}$ lysine. Sections were kept in oven for half an hour at temp $55-60^{\circ} \mathrm{C}$-section were deparaffinised by placing in xylene for $5 \mathrm{~min}$. Slides were then dehydrated by transferring to absolute alcohol, 90\% alcohol, and then to $70 \%$ alcohol followed by rehydrating the sections in running water for $10 \mathrm{~min}$. Endogeneous peroxidase activity was blocked by placing slides in a mixture of methanol and hydrogen peroxide (9:1) for 20 minutes. For antigen retreival, either heat treatment was given by transferring sections to citric acid buffer pH 6 (preheated) in an oven(for ER,PR,Her 2,CK 5/6)or enzyme treatment was given by using enzyme pronase(for EGFR). After cooling sections, sections were rinsed in distilled water and transferred to citric acid buffer for $5 \mathrm{~min}$. Primary antibodies were added to the sections and left for overnight. In case of EGFR, primary antibody was kept for 30 minutes. Secondary antibody tagged with HRP was left for half an hour. Sections were then washed by citric acid buffer for $5 \mathrm{~min}$. Few drops of 3,3 diaminobenzidine (DAB) were added to the sections for 5 minutes. Sections were washed and then counterstained with Haematoxylin. Slides were washed in water, dried and mounted in DPX. Positive and negative controls were used in all of the cases. Wherever there was a discrepancy, fresh slides were prepared and IHC was repeated with both positive and negative controls.

ER and PR positivity was assessed using Allred Score system. Her 2 neu IHC score was calculated combining the intensity of stain and percentage of cells stained. ${ }^{18}$ Score of 0 and 1 were taken as negative, 2 as equivocal and 3 as positive. For CK5/6 and EGFR scoring, any weak or strong cytoplasmic and/or membranous invasive carcinoma cell staining was taken as positive. ${ }^{19}$

A statistical analysis was implemented by using the SPSS 16.0 version software. The Chi square test was conducted to assess the relationship between the immunohistochemical markers and other variables. The Fischer exact test was used when the expected cell counts were less than 5. A p-value less than 0.05 was considered significant.

\section{Results and Observations:}

The study was conducted on a total of 60 cases of breast carcinomas which included 25 cases of triple negative breast carcinomas $(41.7 \%)$ and 35 cases of non triple negative breast carcinomas $(58.3 \%)$. All the patients were female $(100 \%)$. Triple negative breast cancers had a significantly higher tumor grade than non triple negative cancers at presentation. Expression of basal markers was significantly associated with triple negative breast cancers. Comparision of TNBCs and NTNBCs is summarized in Table 1.

Table1: comparision of clinicopathological and immunohistochemical characteristics between TNBC and NTNBC group.

\begin{tabular}{|c|c|c|c|}
\hline CHARACTERISTIC & TNBC (25 cases) & NTNBC (35 cases) & $P$ value \\
\hline \multicolumn{3}{|c|}{ Age } & \multirow{3}{*}{$>0.05$} \\
\hline$\leq 60$ & 20 & 24 & \\
\hline$>60$ & 5 & 10 & \\
\hline \multicolumn{3}{|c|}{ Symptoms } & \multirow{3}{*}{$>0.05$} \\
\hline Discharge & 1 & 4 & \\
\hline Lump & 24 & 31 & \\
\hline
\end{tabular}




\begin{tabular}{|c|c|c|c|}
\hline CHARACTERISTIC & TNBC (25 cases) & NTNBC (35 cases) & $P$ value \\
\hline \multicolumn{3}{|c|}{ Primary Tumor } & \multirow{5}{*}{$>0.05$} \\
\hline T1 & 10 & 13 & \\
\hline $\mathrm{T} 2$ & 12 & 16 & \\
\hline T3 & 1 & 6 & \\
\hline T4 & 2 & - & \\
\hline \multicolumn{3}{|c|}{ Histopathological type } & \multirow{4}{*}{$>0.05$} \\
\hline IDC NOS & 23 & 35 & \\
\hline IDC APO & 1 & - & \\
\hline Medullary & 1 & - & \\
\hline \multicolumn{3}{|c|}{ Tumor Grade } & \multirow{4}{*}{$<0.05$} \\
\hline 1 & - & 5 & \\
\hline 2 & 19 & 28 & \\
\hline 3 & 6 & 2 & \\
\hline \multicolumn{3}{|c|}{ LVI } & \multirow{3}{*}{$>0.05$} \\
\hline present & 10 & 15 & \\
\hline absent & 15 & 20 & \\
\hline \multicolumn{3}{|c|}{ Nodal Stage } & \multirow{5}{*}{$>0.05$} \\
\hline No & 13 & 12 & \\
\hline $\mathrm{N} 1$ & 5 & 13 & \\
\hline N2 & 5 & 10 & \\
\hline N3 & 2 & - & \\
\hline \multicolumn{3}{|c|}{ Tumor Stage } & \multirow{7}{*}{$>0.05$} \\
\hline IA & 7 & 9 & \\
\hline IIA & 9 & 7 & \\
\hline IIB & 2 & 7 & \\
\hline IIIA & 4 & 12 & \\
\hline IIIB & 1 & - & \\
\hline $\mathrm{IIIC}$ & 2 & - & \\
\hline \multicolumn{3}{|c|}{ CK5/6 expression } & \multirow{3}{*}{$<0.05$} \\
\hline positive & 10 & 3 & \\
\hline negative & 15 & 32 & \\
\hline \multicolumn{3}{|c|}{ EGFR expression } & \multirow{3}{*}{$<0.05$} \\
\hline positive & 11 & 6 & \\
\hline negative & 14 & 29 & \\
\hline
\end{tabular}

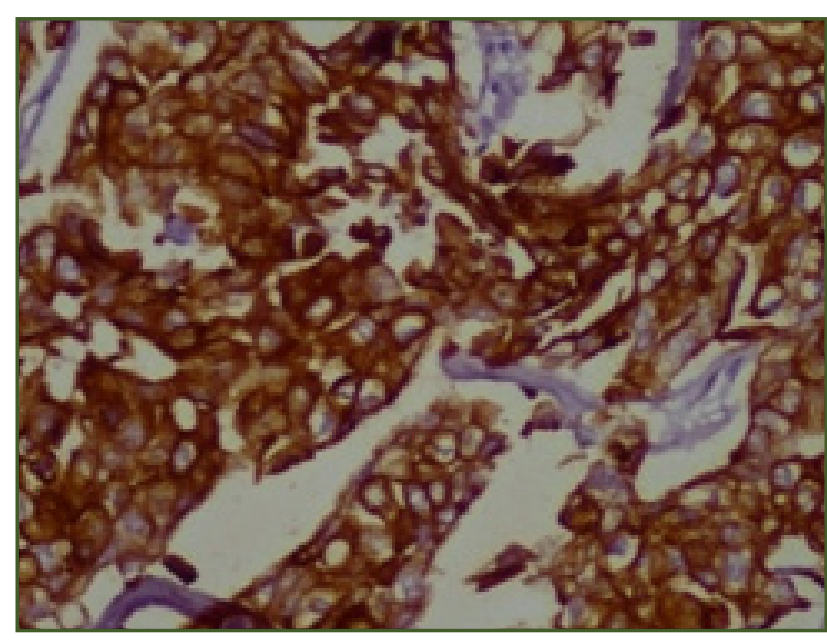

Fig. 1: Photomicrograph showing high power view of strong membranous immunoreactivity for CK $5 / 6$ in breast carcinoma.(40X).

Annals of Applied Bio-Sciences, Vol. 4; Issue 1: 2017

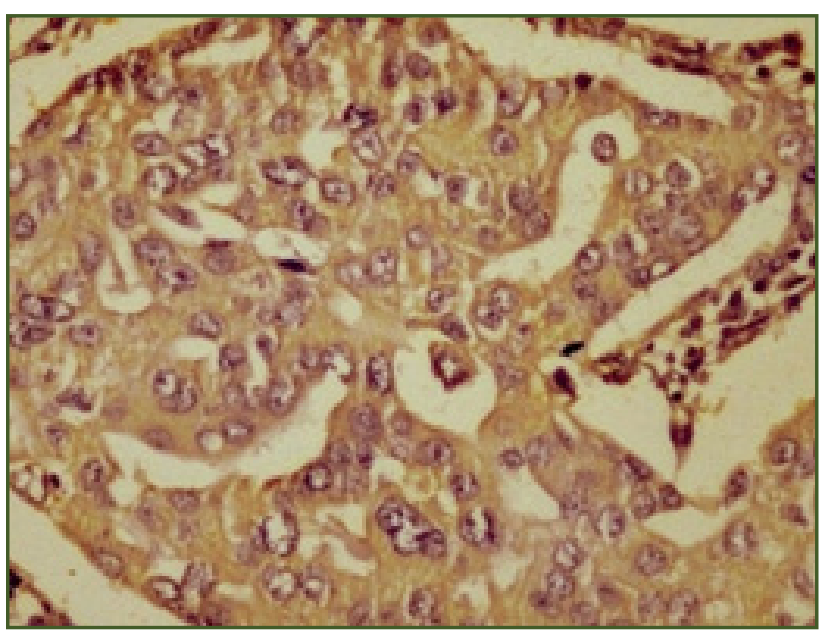

Fig. 2: Photomicrograph showing cytoplasmic and membranous immunoreactivity for EGFR in breast carcinoma.(40X). 


\section{Discussion}

Total number of cases in our study was 60. TNBC comprised $41.66 \%$ of total cases i.e. 25 cases and NTNBC comprised $58.33 \%$ of cases i.e. 35 cases.

Age Distribution: The mean age of TNBC and NTNBC were 47 and 49 years respectively. Various studies show a significant relationship of TNBC with younger age. These include studies of Thike AA et al ${ }^{20}$, Pillai SK et $\mathrm{al}^{21}$ and Rao C et $\mathrm{al}^{22}$.

Symptoms: Most common clinical presentation in our study was left sided lump . Left sided breast lump was the most common symptom in other studies as of Lakshmaiah $\mathrm{KC}$ et $\mathrm{al}^{23}$ and Suresh $\mathrm{P}$ et al. ${ }^{24}$

Primary Tumor: The majority (48\%) of cases from TNBC were in size range of 2-5 cm (T2 stage) while as least number $(8 \%)$ of cases belonged to T4 stage . Majority of cases $(45 \%)$ from NTNBC were also in the T2 stage. No statistical significance was seen between primary tumor and tumor group. Our results are comparable to those of Yuan $\mathrm{N}$ et $\mathrm{al}^{25}$ and Pillai SK et al. ${ }^{21}$

Histological Type: Invasive Ductal carcinomasNOS(IDC-NOS) was the predominant type of tumor in TNBC comprising 23 out of 25 cases $(92 \%)$. There was one case of IDC with apocrine differentiation and one case of medullary carcinoma. All the $35(100 \%)$ cases of NTNBC were of IDC NOS type. There was no statistical correlation between histological type and tumor group. Gaopande V L et $\mathrm{al}^{26}$ and Qui J et al ${ }^{27}$ also found no statistically significant relation between histological type and tumor group.

Tumor Grade: 19 out of 25 cases of TNBC were of Grade 2 ,hence the most common grade constituting $76 \%$ of cases. Grade 3 was seen in 6 cases(24\%). In NTNBC group, Grade 2 was seen in 28 cases accounting for $80 \%$ while it was followed by grade 1 seen in 5 cases(14.28\%). Statistically significant association was found between tumor grade and tumor group with a $\mathrm{p}$ value of 0.037 . Statistically significant association between tumor grade and tumor group was seen by other studies including. Li C Y et al. Li C Y et $\mathrm{al}^{28}$ conducted a study in Tianjin Medical University cancer Institute and Hospital, China in which they found $42.20 \%$ of TNBC cases belonged to Grade 2, and 34.47\% cases belonged to Grade 3 versus $45.66 \%$ of NTNBC belonged to Grade 2 and $32.59 \%$ cases of NTNBC belonged to Grade 3.This association of tumor group with tumor grade was statistically significant. Some other studies which showed significant association between tumor group and tumor grade include those of Nabi MG et $\mathrm{al}^{29}$, Gaopande V L et al ${ }^{26}$ and Albergaria A et al. ${ }^{30}$

Lymphovascular Invasion: The presence of Lymphovascular invasion (LVI) is an independent poor prognostic factor.In our study, 10 out of $25(40 \%)$ TNBC cases and 15 out of $35(42 \%)$ of NTNBC cases had presence of LVI. No statistical significance was found between presence of LVI and tumor group. Our study is comparable to Tawfiq $\mathrm{O}$ et $\mathrm{al}^{31}$ and Hashmi AA et $\mathrm{al}^{32}$ They also did not find any significant association of LVI with tumor group.

Nodal Stage: $52 \%$ i.e. 13 out of 25 of TNBC cases were node negative .In NTNBC group, $37.14 \%$ i.e. 13 out of 35 cases belonged to N1 stage.No association was seen between nodal metastasis and tumor group. No statistical association was seen by $\mathrm{Nabi} \mathrm{MG}^{29}$,Pillai $\mathrm{SK}^{21}$.

Tumor Stage: Tumor Stage is an important prognostic parameter. In our study IIA was the most common stage in TNBC seen in 9 out of 25 cases accounting for 36\% .In NTNBC, majority of the cases i.e. 12 out of 35 cases(34\%) belonged to Stage IIIA.No statistical correlation was seen between the tumor group and tumor stage. No association was also seen by Li C Y et $\mathrm{al}^{28}$ and Yuan $\mathrm{N}$ et $\mathrm{al}^{25}$

CK5/6 AND EGFR Expression: CK 5/6 was expressed in $10(40 \%)$ cases from TNBC group(Figure 1)while as it was expressed in only $3(8 \%)$ cases from NTNBC group. The expression of CK5/6 was significantly higher in the TNBC group than the NTNBC group with a $\mathrm{p}$ value of 0.009. EGFR expression was present in $11(44 \%)$ of TNBC cases(Figure 2) while as it was present in only $6(17 \%)$ of NTNBC cases. EGFR expression was significantly higher in TNBC group as compared to NTNBC group with a $p$ value of 0.040 .

Our study found a significant correlation of basal markers with the negative hormone status. Our results are similar to many other studies carried out in reputable institution across the globe. Pintens $\mathrm{S}$ et $\mathrm{al}^{33}$ carried out a similar study in Belgium. They found basal markers expression in $88 \%$ of TNBC. On comparision with NTNBC, they found high association of basal markers with the TNBC than NTNBC. Similar significant correlation between basal like tumor and negative hormone status was seen by Pillai SK et $\mathrm{al}^{21}$ Choccalingam $\mathrm{C}$ et $\mathrm{al}^{32}$, Rakha EA et $\mathrm{al}^{35}$,Abulkhair $\mathrm{O}$ et $\mathrm{al}^{36}$ and Rao $\mathrm{C}$ et $\mathrm{al}^{22}$.

Hence, in our study there was a significant overlap between triple negative carcinomas and basal like carcinomas. Oncologists may incorporate the use of targeted therapy in basal marker positive cancers as is currently being done in hormone receptor positive cancer. This may benefit a subgroup of patient population after carefully selecting them for this treatment.

\section{Conclusion}

In conclusion, triple negative breast cancers had a significantly higher tumor grade than non triple negative 
cancers at presentation. Expression of basal markers was significantly associated with triple negative breast cancers. Since EGFR was significantly associated with triple negative phenotype, TNBC could potentially benefit from EGFR targeted therapeutic strategies.

\section{Acknowledgements}

Dr. Kousar Sidiq, Senior Resident, Department of Community Medical Scienes, Government Medical College, Srinagar for helping in statistical analysis.

\section{References}

1. Breast Cancer Estimated Incidence, Mortality and Prevalence Worldwide in 2012. Globocan[Internet]. Available from: globocan.iarc.fr/old/FactSheets/cancers/breast-new.asp.

2. Badve S, Dabbas DJ, Schnitt SJ, Baehner FL, Decker T, Eusebi V et al. Basal-like and triple negative breast cancers: a critical review with an emphasis on the implications for pathologists and oncologists. Mod Pathol. 2011; 24:157-67.

3. Elston EW, Ellis IO. Method for grading breast cancer. J Clin Pathol. 1993; 46: 189-190.

4. Sobin LH, Gospodarowicz MK, Wittekind CH. UICC: TNM classification of malignant tumors.7 ed. Oxford: WileyBlackwell; 2009.

5. Sorlie T, Perou CM, Tibshirani R, Aas T, Geisler S, Johnsen $\mathrm{H}$ et al. Gene expression patterns of breast carcinomas distinguish tumor subclasses with clinical implications. Proc Natl Acad Sci USA. 2001; 98:10869-10874.

6. Sasa M, Bando Y, Takahashi M, Hirose T, Nagao T.Screening for basal marker expression is necessary for decision of therapeutic strategy for triple-negative breast cancer. J Surg Oncol.. 2008 Jan 1;97(1):30-4.

7. Perou CM, Sorlie T, Eisen MB, van de Rijn M, Jeffrey SS, Rees CA et al. Molecular portraits of human breast tumours. Nature. 2000; 406:747-752.

8. Bhanvadia V, Goyal P. Basal-like breast cancer: The road less traveled.. Annals Of Pathology And Laboratory Medicine, 2014;1(1), 5-7.

9. Jones C, Nonni AV, Fulford L, Ryder K, Merrett S, ReisFilho JS et al: CGH analysis of ductal carcinoma of the breast with basaloid/myoepithelial cell differentiation. Br J Cancer.2001;85:422-427.

10. Potemski P, Kusinska R, Watala C, Pluciennik E, Bednarek AK, Kordek R.Prognostic relevance of basal cytokeratin expression in operable breast cancer. Oncology.2005; 69:478-485.

11. Kim MJ, Ro JY, Ahn SH, Kim HH,Kim SB,Gong G . Clinicopathologic significance of the basal-like subtype of breast cancer: A comparison with hormone receptor and HER-2/neu-overexpressing phenotypes. Hum Pathol. 2006;37:1217-1226.

12. Fulford LG, Reis-Filho JS, Ryder K, Jones C, Gillett CE, Hanby A et al.Basal-like grade III invasive ductal carcinoma of the breast: Patterns of metastasis and long-term survival. Breast Cancer Res.2007;9:R4.
13. van de Rijn M, Perou CM, Tibshirani R, Haas P, Kallioniemi $\mathrm{O}$, Kononen $\mathrm{J}$ et al.Expression of cytokeratins 17 and 5 identifies a group of breast carcinomas with poor clinical outcome. Am J Pathol. 2002;161:1991-1996.

14. Rakha EA, Putti TC, Abd El-Rehim DM Paish C, Green AR,Powe DG et al. Morphological and immunophenotypic analysis of breast carcinomas with basal and myoepithelial differentiation. J Pathol. 2006;208:495-506.

15. Chang HY, Nuyten DS, Sneddon JB, Hasty T, Tibshirani $\mathrm{R}$,Sorlie $\mathrm{T}$ et al. Robustness, scalability, and integration of a wound-response gene expression signature in predicting breast cancer survival. Proc Natl Acad Sci U S A. $2005 ; 102: 3738-3743$

16. Reis-Filho JS, Milanezi F, Steele D, savage K, Simpson PT, Nesland JM et al. Metaplastic breast carcinomas are basallike tumours. Histopathology. 2006;49:10-21.

17. Jacquemier J, Padovani L, Rabayrol L, Lakhani S, Penault-Llorca F, Denoux $\mathrm{Y}$ et al. Typical medullary breast carcinomas have a basal/myoepithelial phenotype. J Pathol. 2005;207:260-268.

18. Rosai and Ackerman. Surgical Pathology. 10 ed, India: Elsevier; c2011; p1712

19. Cheang MC, Voduc D, Bajdik C, Leung S, McKinney S, Chia SK et al. Basal-Like Breast Cancer Defined by Five Biomarkers Has Superior Prognostic Value than TripleNegative Phenotype.Clin Cancer Res. 2008;14:1368.

20. Thike AA, Cheok PY, Jara-Lazaro AR, Tan B, Tan P, Tan PH. Triple-negative breast cancer: clinicopathological characteristics and relationship with basal-like breast cancer; Modern Pathology . 2010; 23:123-133.

21. Pillai SK, Tay A, Nair S, Leong CE .Triple-negative breast cancer is associated with EGFR, CK5/6 and c-KIT expression. BMC Clinical Pathology. 2012;12:18.

22. Rao C, Shetty J, Prasad KH. Immunohistochemical profile and morphology in triple - negative breast cancers. J Clin Diagn Res.2013 Jul;7(7):1361-5.

23. Lakshmaiah KC, Das U, Suresh TM, Lokanatha D, Babu GK, Jacob LA et al. A Study of Triple Negative Breast Cancer at a Tertiary Cancer Care Center in Southern India. Ann Med Health Sci Res. 2014 Nov-Dec; 4(6):933-937

24. Suresh P, Batra U, and Doval DC .Epidemiological and clinical profile of triple negative breast cancer at a cancer hospital in North India. Indian $\mathrm{J}$ Med Paediatr Oncol. 2013;34(2):89-95.

25. Yuan N, Meng M, Liu C. Clinical characteristics and prognostic analysis of triple-negative breast cancer patients. Mol Clin Oncol. 2014 Ma;2(2):245-251.

26. Gaopande VL, Joshi SS, Kulkarni MM, Dwivedi SS. A clinicopathologic study of triple negative breast cancer .J Sci Soc.: 2015 ;42(1):12-15

27. Qiu J, Xue X, Hu C. Comparison of Clinicopathological Features and Prognosis in Triple-Negative and Non-Triple Negative Breast Cancer. J Cancer. 2016;7(2):167-173 
28. Li CY, Zhang S, Zhang XB, Zhang J. Clinicopathological and Prognostic Characteristics of Triple-Negative Breast Cancer (TNBC) in Chinese patients: A Retrospective study. APJCP. 2013;14(6): 3779-84.

29. Nabi MG, Ahangar A, Wahid MA, Kuchay S . Clinicopathological comparison of triple negative breast cancers with non-triple negative breast cancers in a hospital in North India. Niger J Clin Pract.2015; 18(3):381-6.

30. Albergaria A, Ricardo S,Milanezi F, Carneiro V,Amendoeira I, Vieira D et al. Nottingham Prognostic Index in TripleNegative Breast Cancer: a reliable prognostic tool?.BMC Cancer.2011; 11:299.

31. Tawfik O, Davis K, Kimler BF. Clinicopathological Characteristics of Triple-Negative Invasive Mammary Carcinomas in African-American versus Caucasian Women. Ann Clin Lab Sci . 2010 ; 40(4 ):315-323

32. Hashmi AA, Edhi MM, Naqvi H, Faridi N, Khurshid A , Khan. Clinicopathologic features of triple negative breast cancers: an experience from Pakistan. Diagnostic Pathology.2014;9:43.

33. Pintens S, Neven P, Drijkoningen M, Van Belle V, Moerman P, Christiaens MR et al:Triple negative breast cancer: a study from the point of view of basal CK5/6 and HER-1: J Clin Pathol. 2009;62(7):624-8.

34. Choccalingam C, Rao L, Rao S. Clinico-Pathological Characteristics of Triple Negative and Non Triple Negative High Grade Breast Carcinomas with and Without Basal Marker (CK5/6 and EGFR) Expression at a Rural Tertiary Hospital in India. Breast Cancer (Auckl). 2012; 6: 21-29.

35. Rakha EA, Reis-Filho JS, Ellis IO. Basal-Like Breast Cancer: A Critical Review. Journal of clinical oncology. 2008; 26: 2568-2581.

36. Abulkhair O, Moghraby JS, Badri M. Clinicopathologic features and prognosis of triple-negative breast cancer in patients 40 years of age and younger in Saudi Arabia. Hematology/Oncology and Stem Cell Therapy.2012;5(2):101-6.

*Corresponding author:

Dr. Subuh Parvez Khan, Sher e Kashmir Institute of Medical Sciences, Soura, Srinagar. 190011, INDIA

Phone: +91 9469343742

Email: khansubuh@gmail.com 